\title{
Uses and abuses of intestinal permeability measurements
}

Timothy J. Peters, DSc, FRCP, FRCPATH, INGVAR BJARNASON, MSC, MD

ABSTRACT: Intestinal permeability has been assessed with three different classes of permeability probes, viz various sugar mixtures, ${ }^{51} \mathrm{Cr}$-EDTA and poly(ethylene glycol). The former two methods are having increasing clinical applications in the screening and assessment of small intestinal damage and ${ }^{51} \mathrm{Cr}$-EDTA is now the preferred probe for routine clinical use. Poly(ethylene glycol)s have numerous disadvantages and are not recommended. Probes may be used both in vitro and in vivo and have been applied to a wide variety of clinical problems. In particular, NSAIDinduced enteropathy, a major complication of the chronic administration of these widely-used drugs, was recognized for the first time with ${ }^{51} \mathrm{Cr}$-EDTA permeability measurements. The cytoprotective role of various prostanoids was also clearly demonstrated using ${ }^{51} \mathrm{Cr}$-EDTA. It is anticipated that measurement of intestinal permeability will play an increasing role in clinical and research investigation and in the monitoring of intestinal disease. Can J Gastroenterol 1988;2(3):127-132.

Key Words: ${ }^{51} \mathrm{C} r$-EDTA, Intestinal permeability, Poly(ethylene glycol)s, Probes

MRC Clinical Research Centre, Harrow, Middlesex, UK

Correspondence and reprints: Professor TJ. Peters, Division of Clinical Cell Biology, MRC

Clinical Research Centre, Watford Road, Harrow, Middlesex HAI 3UJ, UK. Telephone

(101) 864.5311 ext 2139

This paper is based on the Avery-Jones Lecture presented at the Central Middlesex Hospital. London in 1986

Received for publication April 26, 1988. Accepted April 27, 1988
$\mathrm{D}$

ETERMINATION OF INTESTINAL permeability in both man and experimental animals is currently finding increasing application, both in research and clinical practice. This review briefly considers the historical development of ideas on mucosal permeability and reviews the current methodology and its application to clinical investigation.

\section{HISTORICAL ASPECTS}

Although there were early studies (1) on the apparent absorption of nonmetabolized sugars and unexplained observations on disacchariduria in intestinal disease (2), the real concepts behind measurement of intestinal permeability were first advanced by Menzies in the 1970s (3). It was, however, only in the 1980s that there was significant interest and progress, and the basis of disorders 
of intestinal permeability were recognized (4). This may have been because of the methodological difficulties inherent in the assay of various urinary saccharides and the uncertainties of metabolism and/or endogenous production of certain of the probe molecules used in such studies $(5,6)$.

There have been reports of altered intestinal permeability in certain experimentally induced mucosal lesions (7) and suggestions of altered permeability allowing antigens access to the mucosa (8). However, these studies used high molecular weight (more than 10,000 dalton) probes and they are likely to have reflected alterations in endocytic activity of the enterocytes, a very minor pathway, rather than changes in trans- and intercellular permeability.

Current interest in measurements of intestinal permeability was also stimulated by the well publicized reports from The Mayo Clinic and subsequently other groups on the use of poly(ethylene glycol)s (9-15). The findings with these polymers and with the sugars produced paradoxical results suggesting increased permeability to small sugar molecules but decreased permeability to large poly(ethylene glycol) molecules in damaged coeliac mucosa. It is now clear that poly(ethylene glycol)s are unsatisfactory probes for measuring mucosal permeability; they are lipophilic and show considerable transfer through normal mucosa and thus uptake is very dependent on mucosal surface area.

Another, more recent objection to the use of poly(ethylene glycol)s is the finding that urinary recovery of the various polymers following intravenous administration is proportional to their molecular size and thus claims of selective alterations in disease may simply reflect. differential urinäry excretion (16). Of even greater concern is the suggestion that poly(ethylene glycol)s may be oxidized enzymatically to potentially highly toxic aldehydes (17). Analytical difficulties and the need for complex mathematical modelling (18) means that these polymers play little role in the routine clinical investigations of disordered permeability. Nevertheless, these reports generated awareness of the importance of measuring intestinal permeability

TABLE 1

Pathways for permeability probes

\begin{tabular}{lll}
\hline Probe (mol wt) & Pathway & Clinical use \\
\hline Rhannose (164) & Transmembrane pores & + \\
Mannitol (180) & Transmembrane pores & + \\
Xylose (150) & Passive carrier mediated & + \\
Lactulose (34) & Intercellular junctions & + \\
Cr-EDTA (342) & Intercellular junctions & - \\
Inulin (5000) & Intercellular junctions & - \\
Cyanocobalamin (1240) & Intercellular junctions \\
Poly(ethylene glycol)s (196-4,000) & Transmembrane, lipophilic & - \\
Horse radish peroxidase (40,000) & Endocytosis & \\
\hline
\end{tabular}

and raised interest in methodological development.

In order to resolve the above paradox and to identify suitable probe molecules, a novel in vitro method was established for the measurement of permeability in intestinal biopsies (19). The procedure involves short term ( 5 to 10 mins) incubation of tissue fragments in oxygenated physiological medium. The technique determines selectively the permeability at the mucosal surface and is equally applicable to both human tissues and samples from experimental animals. It specifically avoids variations of apparent permeability due to gastrointestinal transit, mucosal water flux, blood and lymphatic flow, tissue distribution, renal excretion as well as tissue or luminal metabolism of the probes. Permeability was shown to be inversely linearly related to the log molecular weight of the probe both in normal and coeliac mucosa. Permeability was clearly increased to most probes in mucosa from patients with coeliac disease both in relapse and remission.

Probes used in in vitro studies included ${ }^{51} \mathrm{Cr}$-EDTA, ${ }^{57} \mathrm{Co}$-cyanocobalamin, ${ }^{14} \mathrm{C}$-inulin (19), various labelled sugars (20), peptides (21) and macromolecules $(7,22)$. These studies led to the use of ${ }^{51} \mathrm{Cr}$-EDTA as an in vivo probe for measuring small intestinal mucosa in man (23-25), veterinary practice (26) and experimental animals $(27,29)$ and is currently the most convenient, sensitive and simplest permeability probe used in clinical practice. Recent studies have compared ${ }^{51} \mathrm{Cr}$-EDTA with both sugars and poly(ethylene glycol)s (16). Appropriately selected disaccharides, eg, lactulose, give good agreement with ${ }^{51} \mathrm{Cr}$-EDTA and can be used more readily with children and in repeated studies. Combinations of sugars can be used giving simultaneous determination of active and passive carrier mediated transport, and trans- and intercellular permeability (30). The optimal concentrations, etc, of these test substances, however, remain to be determined.

\section{APPLICATIONS OF PERMEABILITY PROBES}

Table 1 lists the main probes used in vitro and in vivo and the presumed pathways of entry into the mucosa. Although in vitro techniques have been invaluable in formulating concepts of intestinal permeability, in investigating the pathways taken by the individual probes and in localizing the region of gut showing the permeability change, the in vivo methods have generally proved the most clinically useful. Table 2 lists the disorders in which changes in permeability have been investigated.

Inflammatory bowel disease: Consistent increases in permeability have been reported with small bowel inflammation (23,31-35). A normal permeability to oral

\section{TABLE 2}

In vivo studies of intestinal permeability

Coeliac disease

Crohn's disease

Ulcerative colitis

Backwash ileitis

Alcoholic enteropathy

Parenteral nutrition - prolonged starvation

Drug toxicity

Nonsteroidal anti-inflammatory drugs

and prostaglandins

Rheumatoid and osteoarthritis

Schizophrenia

Dermatitis herpetiformis

Atopic eczema, food intolerance

Infective enteritides

Cystic fibrosis 
${ }^{51} \mathrm{Cr}$-EDTA virtually excludes small bowel inflammation in Caucasians and is thus a useful screening test for small bowel disease. There is some controversy as to whether the in vivo permeability tests are increased (34) or normal (23) in ulcerative colitis. This may relate to the presence of various osmotic fillers (either absorbed or nonabsorbed) adminstered concomitantly with the probes in the various studies as well as the extent and activity of the colitis. Recent studies have measured large bowel permeability by direct rectal installation of the ${ }^{51} \mathrm{Cr}$-EDTA with urinary radioassay $(36,37)$. Clearly, saccharide probes are subject to rapid bacterial degradation and are unsuitable in this type of test. The clinical value of direct rectosigmoid permeability measurements are not yet established. They may, however, be of use in distinguishing functional bowel disorders from inflammatory bowel disease and in assessing response to treatment.

NSAID enteropathy: One of the most useful applications of permeability measurements particularly the ${ }^{51} \mathrm{Cr}$-EDTA test has been the identification of chronic smalb bowel enteropathy due to nonsteroidal anti-inflammatory drugs (NSAIDs) (38). Nonspecific gastrointestinal symptoms have long been recognized as a frequent side effect of these drugs. An increased incidence of perforation (39) together with subjective gastroscopy findings suggested that the toxicity was confined to the stomach. However, recent studies (40-42) have shown that chronic NSAID therapy is frequently associated with small intestinal inflammation, ulceration and blood loss. Increased permeability is the initial lesion and probably is the key pathogenic mechanism of this important toxic effect. The similarities between this lesion and Crohn's disease are close and further studies of NSAID enteropathy should, both in man and experimental animals, considerably enhance understanding of the etiology, pathogenesis and treatment of this important challenge to gastroenterologists.

Coeliac disease: The increased permeability in patients with coeliac disease in relapse has already been noted ( 24 , 43-45). Increased permeability also occurs in the associated dermatitis herpe- tiformis $(46,47)$. Increased permeability in coeliac disease in relapse correlates with intraepithelial lymphocyte count suggesting a causal relationship (24). The increased permeability has been confirmed in vitro (18) and there is clearly no cut-off over the molecular weight range 300 to 5000 daltons. There is, however, disagreement over the response to treatment. Some studies suggest a return to normal with a gluten-free diet (48) but more recent studies both in vitro and in vivo indicate a reduced but persisting abnormality in these patients (49) even where the mucosa appears histologically normal. However, as very minor histological abnormalities (50) or changes in cell proliferation, only demonstrable by very sensitive biochemical methods (51), may be accompanied by increased permeability, the question remains open as to whether the permeability defect represents a primary or secondary lesion. Preliminary results indicate that coeliac patients treated with a nonantigenic elemental diet show a return to normality in their gut permeability.

Chronic psychiatric disorders: Dohan and colleagues (52) have claimed a relationship between coeliac disease and schizophrenia invoking the concept of exorphins associated with increased intestinal permeability (53). A report by Wood and colleagues (54) suggested that increased permeability was indeed present in approximately one-third of a series of chronic psychiatric inpatients. However, their low and very variable recovery of sugar probes indicates that the results should be interpreted with caution. In addition, these subjects were receiving a variety of unspecified drugs known to affect intestinal permeability, gastrointestinal transit and renal function. A more detailed study using ${ }^{51} \mathrm{Cr}$ EDTA has failed to confirm these conclusions (55).

Miscellaneous disorders: Increased permeability is a highly sensitive measure of disruption of the normal mucosal barrier function of the small intestine and it is therefore not surprising that many potential toxic agents cause increased permeability. NSAIDs almost invariably increase permeability but alcohol abuse $(56,57)$, cytotoxic drugs (27,58-62), cholecystokinin and bile salts
(63), various detergents, $(14,26,64,65)$. gold compounds $(66)$, chelators $(67,68)$, ischemia (69) and dietary idiosyncrasies (70) are also frequently accompanied by increased permeability without necessarily causing gastrointestinal symptoms. Increased permeability in premature infants (71) and following starvation (72) has been reported.

There have been several suggestions that increased gut permeability is a major pathogenic factor in a variety of allergic disorders particularly eczema. Measurements of permeability do show a higher prevalence of abnormal results, particularly in patients with severe systemic disease (73-77). Some of the patients show jejunal abnormalities and an increased prevalence of coeliac disease in these patients had been noted. It is unlikely that increased permeability represents a primary defect but merely reflects mucosal abnormalities associated with severe systemic disease. Summarizing the various reports, the data suggest that increased permeability is more frequently observed in children than in adults with eczema; the former more frequently show a dermatological response to dietary exclusion therapy.

Increased permeability has been consistently demonstrated in various small bowel infective enteropathies $(74,78)$ due both to viral and bacterial infections. The time course of recovery has not been adequately documented but in certain individuals may be persistent and present clinically as irritable bowel syndrome.

\section{OUTSTANDING QUESTIONS}

Although the permeability pathways for the various probes are being increasingly understood, further studies are clearly indicated. Poly(ethylene glycol)s enter via a lipophilic pathway but whether specific domains of the cell membranes are involved has not been identified. Certain monosaccharides, eg, mannitol, enter via so-called 'pores' but the ultrastructural and biochemical basis for this physiological concept has not been identified.

Although various saccharides have been used in research they are not very suitable for routine clinical use. The analytical techniques are demanding 
but, in addition, bacterial and cellular metabolism coupled with endogenous formation of cer tain sugars limit their use. The poor urinary recoveries of certain intravenously administered sugar probes is also a cause of concern. There is thus a need for a readily assayed, possibly radiolabelled, probe for assessing poremediated intestinal uptake.

The uniquely valuable properties of ${ }^{51} \mathrm{Cr}$-EDTA have been discussed in detail elsewhere (4) but there is need for an assay procedure or alternative

\section{REFERENCES}

1. McCance RA, Madders K. The comparative rate of absorption of sugars from the human intestine. Biochem J 1930;24:795-804.

2. Weser E, Sleisenger MH. Lactosuria and lactase deficiency in adult coeliac disease, Gastroenterology 1965;48: 571-8.

3. Menzies IS. Absorption of intact oligosaccharides in health and disease. Biochem Soc Trans 1974;2:1042-7.

4. Peters TJ, Bjarnason I. Intestinal permeability. In: Hunter JO, Alun-Jones $\mathrm{V}$, eds. Food and the Gut. London: Balliere Tindall, 1985:30-44.

5. Laker MF, Bull HI, Menzies IS. Evaluation of mannitol for use as a probe marker of gastrointestinal permeability in man. Eur J Clin Invest 1982;12:485-91.

6. McIntosh JC. The excretion of sugars in human urine. Clin Chim Acta 1984;143:169-72

7. Keljo DJ, Butler DG, Hamilton JR. Altered jejunal permeability to macromolecules during viral enteritis in the pig. Gastroenterology 1985;88:998-1004.

8. Bjarnason I, Peters T]. Helping the mucosa make sense of macromolecules. Gut 1987;28:1057-61.

9. Chadwick VS, Phillips SF, Hofmann AF. Measurement of intestinal permeability using low molecular weight polyethylene glycols (PEG 400). II. Applications to normal and abnormal permeability states in man and animals. Gastroenterology 1977;73:247-51.

10. Robinson GM, Orrego H, Israel Y, Devenyi P, Kapur BM. Low molecular weight polyethylene glycol as a probe of gastrointestinal permeability after alcohol ingestion. Dig Dis Sci 1981;26:971-7.

11. Tagesson C, Andersson PA, Andersson T, Bolin T, Kallberg M, Sjodahl R. Passage of molecules through the wall of the gastrointestinal tract. Measurement of intestinal permeability to probe which does not use a radiolabelled tracer. Immunoassay with monoclonal antibodies offers a potentially useful approach (79). The exact pathway of these probes through the mucosa are uncertain, eg, whether there is selective uptake along the villus and the nature of the anatomical barrier, presumed to be the intercellular tight junction, are uncertain. Suitable ultrastructural studies with in vitro measurement of permeability should prove useful.

More detailed knowledge of the bio- chemical basis of mucosal integrity is needed. The observation that orally administered prostaglandins protects the small intestine against NSAID-induced injury (30) clearly has therapeutic implications but also implicates prostaglandins in the maintenance of the mucosal permeability barrier (80). This may also be relevant to the treatment of inflammatory bowel disease and indicate the biochemical processes underlying the structural integrity of the gut and offers exciting future research projects. polyethylene glycols in the 634-1338

Dalton range (PEG 1000). Scand J

Gastroenterol 1983; 18:481-6.

12. Urband E, Zingery AA, Michel AM, Whitney SC. Permeability of polyethylene glycol in remnant small bowel after massive intestinal resection. Proc Exp Biol Med 1983;172:207-13.

13. Magnusson KE, Sundqvist T.

Mathematical modelling for determining intestinal permeability using polyethylene glycol. Gut 1984;25:428-9.

14. Lifschitz $\mathrm{CH}$, Irving CS, Marks LM, Klein PD, Finegold MJ, Nichols BL. Polyethylene glycol polymers of low molecular weight as probes of intestinal permeability. II. Application to infants and children with intestinal disease. J Lab Clin Med 1986;108:37-43.

15. Seidman EG. Hanson DG. Walker WA. Increased permeability to polyethylene glycol 4000 in rabbits with experimental colitis. Gastroenterology 1986;90:120-6.

16. Maxton DG, Bjarnason I, Reynolds AP, Catt SD, Peters TJ, Menzies IS. Lactulose, ${ }^{51} \mathrm{Cr}$-labelled ethylene diamine tetracetate, L rhamnose and poly ethylene glycol 500 as probe markers for assessment in vivo of human intestinal permeability. Clin Sci 1986;71:71-80

17. Hunt OF, Giordani AB, Rhodes G, Herold DA. Mixture analysis by triple quadruple mass spectrometry. Clin Chem 1982;28:2387-92.

18. Sundqvist T, Magnusson KE. Modelling of intestinal permeability in man to polyethylene glycols (PEG 400 and PEG 1000). Acta Physiol Scand 1985; 125:289-96.

19. Bjarnason I, Peters TJ. In vitro determination of small intestinal permeability: Demonstration of a persistent defect in patients with coeliac disease. Gut 1984;25:145-50.

20. Dawson DJ, Burrows PC, Mahon M, Notman JA, Lobley RW, Holmes R. Validation of sugars as permeability probes in coeliac disease. Clin Sci 1984;67:64P
21. Dawson DJ, Dunne AM, Lobley RW, et al. Mucosal permeability to gliadin is normal in treated coeliac disease. Gut 1986;27:1273-4.

22. Jackson D, Walker-Smith JA, Phillips AD. Passive diffusion in small intestinal mucosa in childhood. Histopathology 1982;6:689-707.

23. Bjarnason I, O'Morain C, Levi A]. Peters T]. Absorption of ${ }^{51}$ Chromiumlabelled ethylenediamine tetracetate in inflammatory bowel disease. Gastroenterology 1983;85:318-22.

24. Bjarnason I, Peters T, Veall N. A persistent defect in intestinal permeability in coeliac disease demonstrated by a ${ }^{51} \mathrm{Cr}$-labelled EDTA absorption test. Lancet 1983;i:323-5.

25. Bjarnason I, Peters T]. Intestinal permeability: Clinical correlates. Dig Dis 1986;4:83-92.

26. Hall EJ. Investigation into the pathogenesis of a wheat-sensitive enteropathy in Irish setter dogs, PhD thesis, Unversity of Liverpool, England. 1988.

27. Bjarnason I, Smethurst P, Levi AJ, Peters TJ. Intestinal permeability to ${ }^{51} \mathrm{Ct}$ EDTA in rats with experimentally induced enteropathy. Gut 1985;26:579-85.

28. Ramage JK, Jenkins RT, Hunt RH Perdue MH. Permeability of inflamed jejunum to ${ }^{51} \mathrm{Cr}$-EDTA in the in vivo rat Gut 1986;27: A 1261

29. Delahunty T, Hollander D A comparison of intestinal permeability between humans and three common laboratory animals. Comp Biochem Physiol 1987;86A:565-7.

30. Bjarnason I, Smethurst P, Clarke P, Menzies IS, Levi AJ, Peters TJ. Effect of prostaglandin on indomethacin-induced increased permeability in man. Scand J Gastroenterol. (In press)

31. Pearson ADJ, Eastham EJ, Laker MF, Craft AW, Nelson R. Intestinal permeability in children with Crohn's disease and coeliac disease. Br Med J $1982 ; 285: 20-1$. 
32. Ukabam SO, Clamp JR, Cooper BT, Abnormal small intestinal permeability to sugars in patients with Crohn's disease of the ileum and colon. Clin Sci 1982;62:21-2P.

33. Ukabam SO, Clamp JR, Cooper BT. Abnormal small intestinal permeability to sugars in patients with Crohn's disease of the terminal ileum and colon. Digestion 1983:27:70-4.

34. Jenkins RT, Goodacre RL, Reilly RM, Hunt RH, Bienenstock J. Intestinal permeability in Crohn's disease, ulcerative colitis and gluten-sensitive enteropathy. Gastroenterology 1985;88:1433.

35. Sanderson IR. Boulton P. Menzies I, Walker-Smith JA. Improvement of abnormal lactulose/rhamnose permeability in active Crohn's disease of the small bowel by an elemental diet. Gut 1987;28: 1073-6.

36. Rask-Madsen J, Schwarz M. Absorption of ${ }^{51} \mathrm{Cr}$ EDTA in ulcerative colitis following rectal instillation. Scand J Gastroenterol 1970;5:361-8.

37. O'Morain CA, Abelow AC, Chervu LR, Fleischner GM, Das KM. Chromium 51-ethylene diamine tetracetate test: A useful test in the assessment of inflammatory bowel disease. J Lab Clin Med 1986;108:430-5.

8. Bjarnason I, Williams P, So A, et al. Intestinal permeability and inflammation in patients with rheumatoid arthritis; effects of non-steroidal anti-inflammatory drugs. Lancet 1984;ii:1171-4.

39. Langman MJ, Morgan L, Worrall A. Use of anti-inflammatory drugs by patients admitted with small or large bowel perforations and haemmorrhage. Br Med J 1985; 290:347-9.

40. Bjarnason I, Zanelli G, Prouse P, et al. Blood and protein loss via small intestinal inflammation induced by non-steroidal anti-inflammatory drugs. Lancet 1987;ii:711-4.

41. Bjarnason I, Zanelli G, Smith T, et al. Non steroidal anti inflammatory drug induced intestinal inflammation in humans. Gastroenterology 1987;93:480-9

42. Madok R. Mackenzie JA, Lee FD, Bruckner FE, Terry TR, Sturrock RD. Small bowel ulceration in patients receiving non-steroidal anti-inflammatory drugs for theumatoid arthritis. QJ Med 1986;58:53-8.

43. Bjarnason I, Marsh MN, Levi AJ, Price A. Peters TJ. Mucosal recovery and permeability in gluten-sensitive enteropathy. Gut 1984:25:A573.

44. Dawson DJ, Dunne AM, Lobley RW. Notman J, Mahon M, Holmes R. Mucosal permeability to sugars in vitro in coeliac and Crohn's disease. Gut 1986;27:A 1269
45. Behrens RH, Szaz KF, Northrop C. Elia M, Neale G. Radionucleotide tests for the assessment of intestinal permeability. Eur J Clin Invest 1987:17:100-5

46. Bjarnason I, Goolamali SK, Levi AJ, Peters TJ. Intestinal permeability in patients with atopic eczema. $\mathrm{Br}$ ] Dermatol 1985;112: 291-7.

47. Hamilton I, Fairis GM, Rothwell J. Cunliffe WJ, Dixon MF, Axon ATR. Small intestinal permeability in dermatological disease. QJ Med 1985;256:559-67.

48. Hetzel PAS, Labrooy JT, Bellon M, et al. The ${ }^{51} \mathrm{Cr}$ EDTA absorption test in coeliac patients treated with a gluten free diet. IRCS ] Med Sci 1986; 14:1183-4.

49. Peters T], Bjarnason L. Coeliac syndrome: Biochemical mechanisms and the missing peptidase hypothesis revisited. Gut 1984:25:913-8.

50. Juby LD, Dixon MF, Axon ATR. Abnormal intestinal permeability and jejunal morphometry. J Clin Path 1987; $40: 714-8$.

51. Raja KD, Gregory H, Peters TJ. Effect of mouse epidermal growth factory/ urogastrone (EGF/UG) on duodenal ${ }^{59} \mathrm{Fe}^{3+}$ absorption in mice, Clin Sci 1987;73:32P.

52. Dohan FC. The possible pathogenic effect of cereal grain in schizophrenia. Acta Neurol (Naples) 1976;31:195-205.

53. Ziodrou C, Streaty RA, Klee WA. Opioid peptides derived from food proteins. The exorphins. ] Biol Chem 1979:254:2446-9.

54. Wood NC, Hamilton I, Axon ATR, et al. Abnormal intestinal permeability; an aetiological factor in chronic psychiatric disorders, Br J Psychiatr 1987;150:853-6.

55. Bjarnason I, Marsh MN, Levi AJ, Crow T], Goolamali SK, Peters, T]. Intestinal permeability in coeliac sprue (CS). dermatitis herpetiformis (DH), schizophrenia (S) and atopic eczema (AE). Gastroenterology 1984:86:1029.

56. Draper LR, Gyure LA, Hall JG, Roberson D. Effect of alcohol on the integrity of the intestinal epithelium. Gut 1983;24:399-404.

57. Bjarnason I, Ward K, Peters TJ. The leaky gut of alcoholism: Possible route of entry for toxic compounds. Lancet 1984;i: 179-82.

58. Selby PJ, Lopes N, Mundy J, Crofts M, Millar JL. McElwain TJ. Cyclophosphamide priming reduces intestinal damage in man following high dose melphalan chemotherapy. Br J Cancer 1987;55:531-3.

59. Sandhu JS. Fraser DR. Assessment of intestinal permeability in the experimental rat with ${ }^{3} \mathrm{H}$-cellobiotol and ${ }^{14} \mathrm{C}$-mannitol. Clin Sci 1982;63:311-6.
60. Sandhu JS. Fraser DR. Effect of dietary cereals on intestinal permeability in experimental enteropathy in rats. Gut 1983;24:825-30.

61. Parrilli G, Iaffaioli RV, Capuano O. Budillon G, Bianco AR. Changes in intestinal permeability to lactulose induced by cytotoxic chemotherapy. Cancer Treat Rep 1982,66:1435-6.

62. Selby P, McElwain TJ, Crofts M, Lopes N, Mundy J. "Cr EDTA test for intestinal permeability. Lancet 1984;ii:39.

63. Budillon G, Parrilli G, D'Agostino L, Capuano G, Mazzacca G, Menzies IS Cholecystokinin and human intestinal permeability. Digestion 1980;20:68-72

64. Ecknauer R, Buck B, Breitig D. An experimental model for measuring intestinal permeability. Digestion 1983;26:24-32.

65. Tageson C, Franzen L, Dahl G, Westrom B. Lysophosphatidylcholine increases rat ileal permeability to macromolecules. Gut 1985:26:369-77.

66. Behrens R, Devereaux M, Hazleman B, Szaz K, Calvin J, Neale G. Investigation of Auranofin-induced diarrhoea. Gut, 1986;27:59-65.

67. Cassidy MM, Tidball CS. Cellular mechanisms of intestinal permeability alterations produced by chelation depletion. J Cell Biol 1967;32:685-98.

68. Aronson A, Rogerson KM. Effect of calcium and chromium chelates of EDTA on intestinal permeability and collagen. Tox App Pharm 1972;21:440-53.

69. Kingham JGC, Whorwell PJ, Loehry CA. Small intestinal permeability. Gut 1976;17:354-61.

70. Dumont GCL, Beach RC, Menzies IS. Gastrointestinal permeability in food allergic exzematous children. Clin Allergy 1984; 14:55-9.

71. Weaver LT, Laker MF, Nelson R. Intestinal permeability in the new born. Arch Dis Child 1984;59:236-41.

72. Elia M, Goren A, Behrens R, Barber RW, Neale G. Effect of total starvation and very low calorie diets on intestinal permeability in man. Clin Sci 1987:73:205-10.

73. Ukabam SO, Mann RJ, Cooper BT. Small intestinal permeability to sugars in patients with atopic eczema. $\mathrm{Br} \mathrm{J}$ Dermatol 1984;110: 649-52.

74. Forget P, Sodoyez-Goffaux F, Zapitelli A. Permeability of the small intestine to SI $\mathrm{Cr}$ EDTA in children with acute gastroenteritis or eczema. J Pediatr Gastroenterol Nutr 1985;4:393-6.

75. McCalla R, Savilahti E. Perkkio M, Kuitunen P, Backman A. Morphology of the jejunum in children with eczema due to food allergy. Allergy 1980;35:563-71.

76. Falth-Magnusson K, Kjellman NIM, 
Magnusson KE, Sundqvist T. Intestinal permeability in healthy and allergic children before and after sodium chromoglycate treatment assessed with different sized poly-ethylene glycols (PEG 400 and PEG 1000). Clin Allergy 1984:14:277-86.

77. Newton JA, Maxton DG, Bjarnason I, Reynolds AP, Menzies IS, Thompson
$\mathrm{PPH}$. Intestinal permeability in atopic eczema. Clin Sci 1984;67:65P.

78. Noone C. Menzies IS, Banatvala JE.

Scopes JW. Intestinal permeability and lactose hydrolysis in human rota viral gastroenteritis assessed simultaneously by non-invasive differential sugar permeation. Eur J Clin Invest $1986 ; 16: 217-25$
79. Reardan DT, Meares CF. Goodwin DA. et al. Antibodies against metal chelates. Nature 1985;316:265-7.

80. Bjarnason 1, Williams P. Smethurst P. Peters TJ, Levi AJ. Effect of non-steroidal anti-inflammatory drugs and prostaglandins on the permeability of the human small intestine. Gut 1986;27:1292-7. 


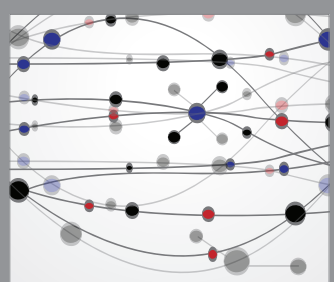

The Scientific World Journal
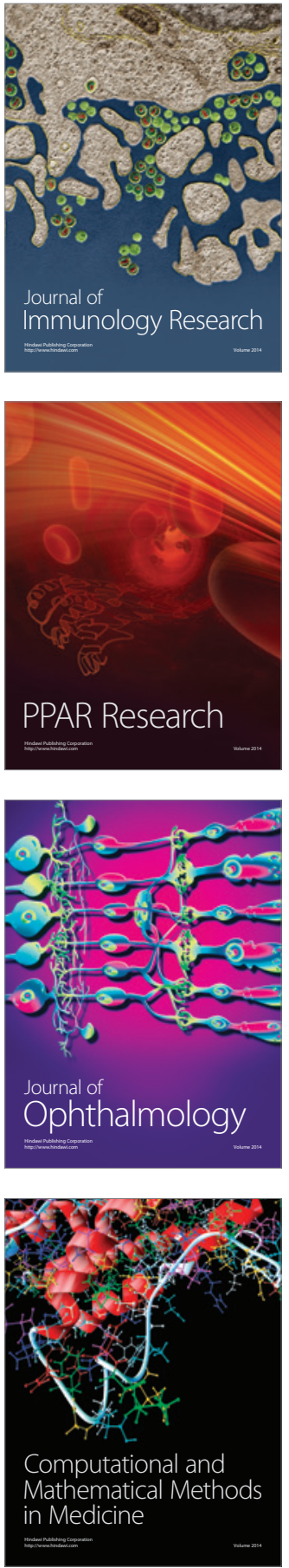

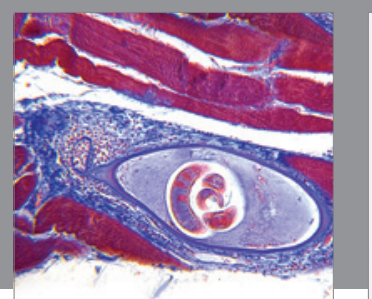

Gastroenterology Research and Practice

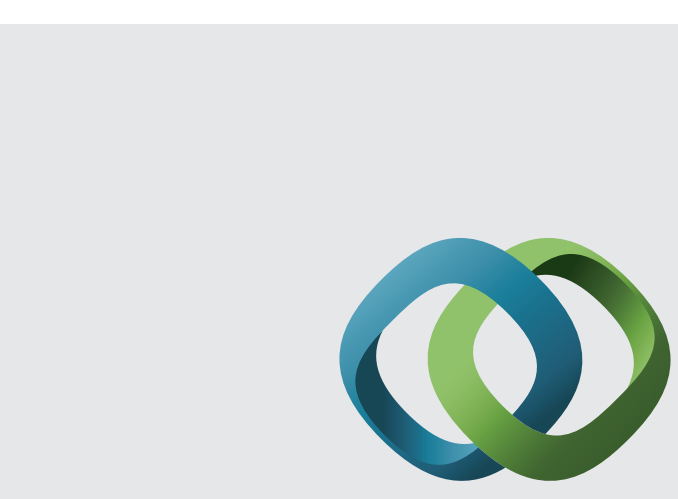

\section{Hindawi}

Submit your manuscripts at

http://www.hindawi.com
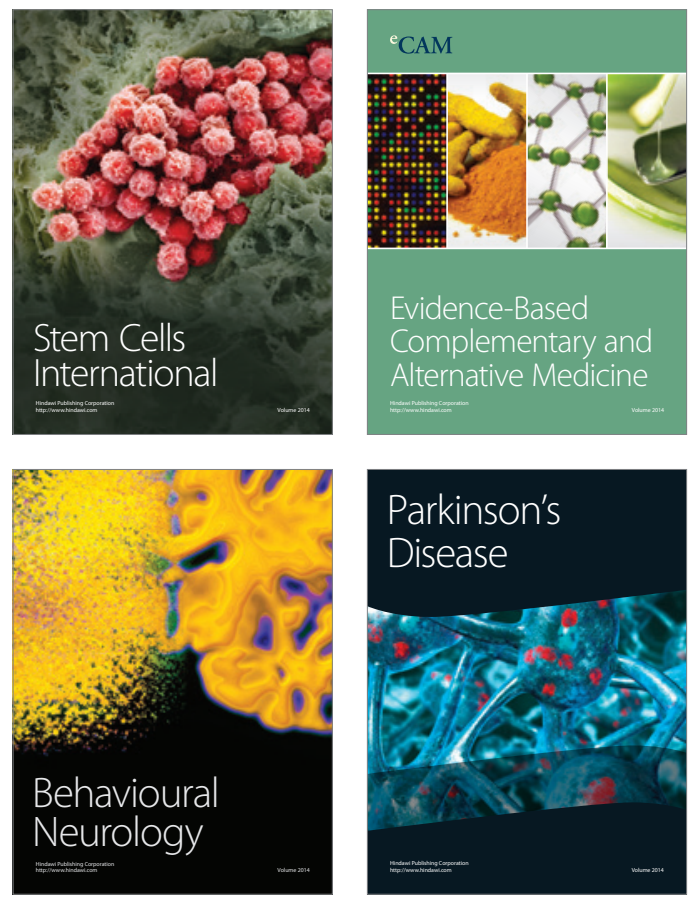
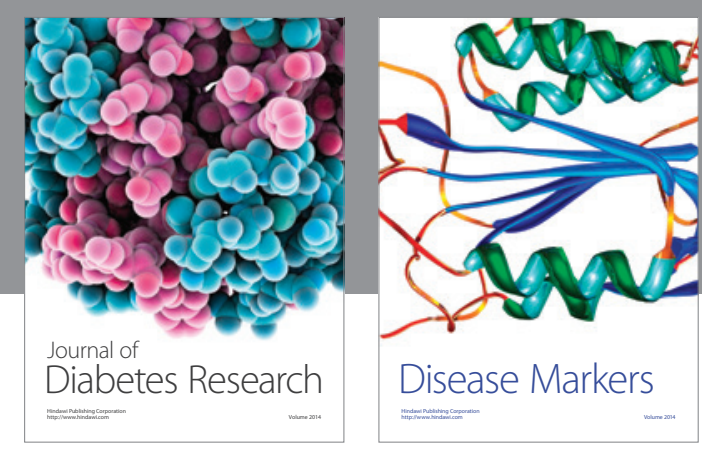

Disease Markers
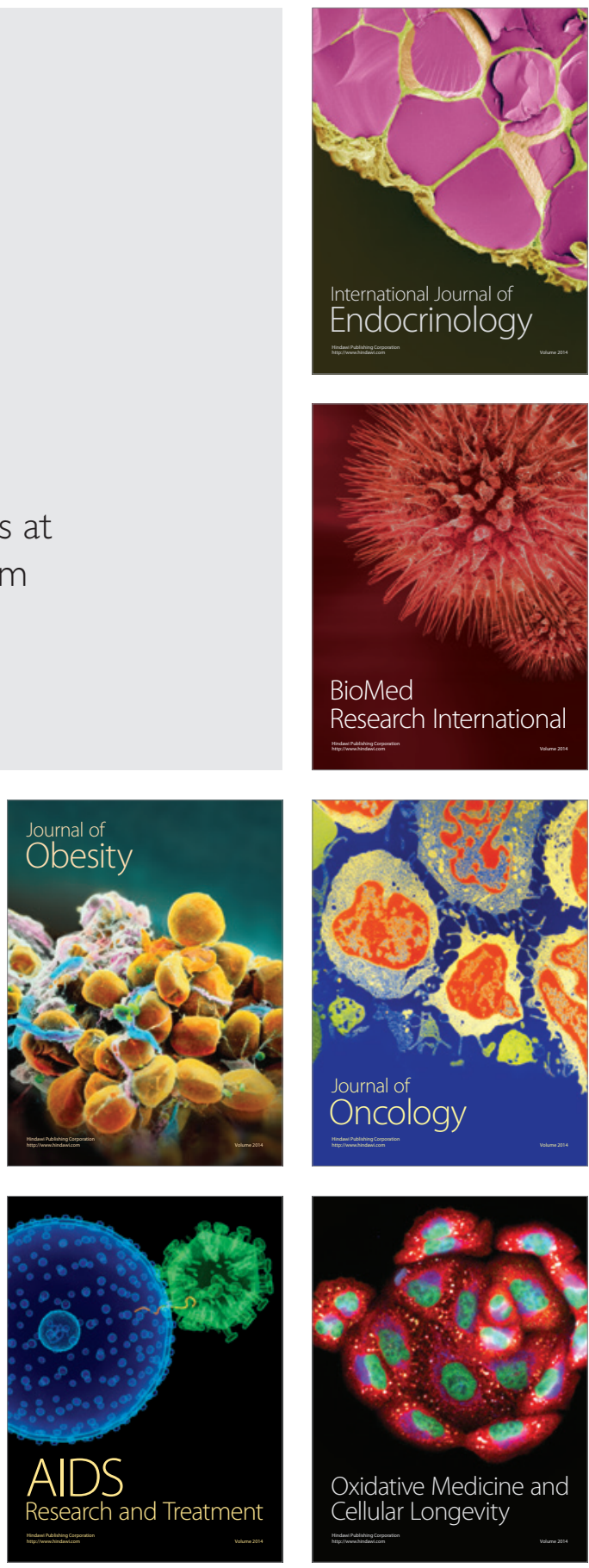